\title{
Development of ITM Oxygen Technology for Integration in IGCC \& Other Advanced Power Generation Systems (ITM Oxygen)
}

\author{
Technical Progress Report
}

for the period

October - December 2000

Robin E. Richards, Ph.D.

8 May 2001

DE-FC26-98FT40343

Air Products and Chemicals, Inc.

7201 Hamilton Blvd.

Allentown, PA 18195 


\section{Task 1.1: Optimize ITM Oxygen Materials}

The Pennsylvania State University (Penn State) further extended its creep rate measurement capabilities for ITM Oxygen materials by developing a quantitative tensile testing method, using Penn State's Advanced Fiber Tester apparatus and a new sample type fabricated by Ceramatec, Inc. These new tensile creep samples are prepared from ceramic tape, laser cut into the shape required while in the green state. Quantitative tensile creep testing is underway for the ITM Oxygen material AP2K, and initial results agree well with Penn State's previous testing performed on bend-bar samples. Penn State's advances in experimental equipment and technique enable creep rates less than the current target value to be measured at low stress.

Penn State commissioned the new test unit that measures the high-temperature behavior of ITM Oxygen materials under oxygen permeation conditions. Penn State, Air Products and McDermott Technology, Inc. collaborated to provide mechanical models for analysis and interpretation of experimental data, and further definition of experimental conditions. Air Products and Ceramatec, Inc. continued their measurements of physical and chemical property data for the ITM Oxygen material AP2K.

\section{Task 1.2: Lifetime Testing of Optimized ITM Oxygen Materials}

Air Products performed several AP2K subscale membrane flux tests in the Vacuum PermeateEquipped Short Loop Test Rig units. These tests were performed at the full operating temperature, at a feed-air pressure ratio of approximately 14 and driving forces considered typical for commercial process conditions. Air Products achieved the ITM Oxygen flux target for Phase I set by the economic objective of producing lower cost oxygen compared to conventional technology. Air Products also performed additional oxygen flux tests of laboratory-scale, supported, thin-film membranes with an atmospheric pressure feed and a vacuum-permeate and performance tests of ceramic-to-metal seal assemblies for the ITM Oxygen module. Ceramatec prepared the membrane samples under Task 3.2, using its baseline ceramic processing procedures.

Eltron Research, Inc. prepared additional ceramic powder lots of the final compositions selected for its designed experiment study of ITM Oxygen material compositions, and prepared membrane samples for oxygen flux tests. Several flux tests were completed at Eltron Research for the designed experiment and for the selection of preferred catalysts that enhance the rate of oxygen exchange between the gas phase and the membrane.

\section{Task 2.1: Gas Turbine Integration}

Concepts NREC, Inc. continued to provide support for Task 2.6.1 Process Engineering and Economic Evaluation for the IGCC Application by collaborating with Air Products on turbine engine performance calculations. Concepts NREC also completed its parametric design calculations for the precombustor located upstream of the ITM Oxygen process vessel, which directly heats the extracted compressed air stream. The calculations and precombustor 
design were based on the final conditions iterated between Texaco, Inc., Air Products, and Concepts NREC for the IGCC economic study under Task 2.6.1, around the state-of-the-art engine selected under Task 2.1.3. Concepts NREC's estimated precombustor cost was incorporated into the base case ITM Oxygen-integrated IGCC facility cost under Task 2.6.1.

\section{Task 2.3: Thermal and Mechanical Analysis of Membranes and Seals}

McDermott Technology developed thermal and mechanical models and completed analyses of several initial and trial experiments performed by Penn State with the new test unit that measures the hightemperature behavior of ITM Oxygen materials under oxygen permeation conditions (see Task 1.2 above).

\section{Task 2.4: Conceptual Process Vessel Design Engineering}

McDermott Technology, Inc. developed further its design and calculation procedures for specifying conceptual designs and cost estimates of commercial-size ITM Oxygen process vessels. McDermott Technology also completed a conceptual design for an alternate vessel configuration and mapped out the costs for the same configuration for a range of vessel sizes, to determine the shape of the cost curve and the scaling factor up to an oxygen production of nominally 500 TPD. The preliminary cost estimates are consistent with the ITM Oxygen economic target of producing lower cost oxygen compared to conventional technology. McDermott is continuing to examine options for commercial process vessels to house full-size ITM Oxygen membrane modules, by evaluating the sensitivity of vessel costs to several design parameters identified during a joint review meeting held in November between Air Products, Ceramatec, and McDermott Technology.

\section{Task 2.5: Mass Transfer Modeling of Membranes}

Air Products revised the model for predicting oxygen flux for ITM Oxygen membranes based on the material AP2K. The AP2K properties required for the model revision were derived from statistical analysis of additional oxygen flux data measured under Task 1.2, for supported, thin-film AP2K membranes. The revised flux model closely predicted the flux measured for AP2K subscale membrane tests performed in the Vacuum Permeate-Equipped Short Loop Test Rigs under Task 1.2.

\section{Task 2.6: Process Engineering and Economic Evaluation}

Under Task 2.6.1, Texaco and Air Products are performing a collaborative process engineering and economic evaluation of IGCC power plants employing Texaco's gasification technology. Texaco completed the overall cost and performance summaries for both the ITM Oxygen-integrated base case and the cryogenic ASU-integrated base case for the IGCC study. Air Products provided the utility information and cost estimates for the cryogenic ASU and ITM Oxygen unit. The economic benefits for the ITM Oxygen-integrated facility include a 7\% improvement (reduction) in overall plant specific cost at $\$ 1,020 / \mathrm{kW}$ and a greater than $30 \%$ reduction in the specific cost of the air separation unit compared 
to the cryogenic ASU. Texaco and Air Products will meet in the second quarter of FY01 to finalize the base case study, and identify and construct any additional cases for study in Task 2.6.1.

\section{Task 3.1: Membrane Design and Engineering}

McDermott Technology is nearing completion of assembling the hardware for the "pressure-collapsetest," a candidate test for validating its approach and property assumptions used for mechanical modeling of ITM Oxygen membrane structures. McDermott Technology has successfully strain-gauged the membrane test sample for the initial shakedown experiment.

Air Products developed a methodology to determine the optimum (i.e., full-size) membrane module size, based on economic and engineering models. The preliminary results indicate that an optimum membrane module size does exist. The full-size membrane module specification will be set once sensitivities are analyzed and understood, including fabrication yield.

\section{Task 3.2: Membrane Fabrication}

Ceramatec continued its baseline ceramic processing development for the ITM Oxygen full-size membrane, and processed multiple lots of membranes. Scaleup of baseline membrane-processing throughput was sustained, with a minor increase in the total membrane area processed during OctoberDecember when compared to the prior quarter. Several planned changes to the baseline unit operations were completed successfully in order to improve quality and/or productivity. These changes included the use of new ceramic processing tools in the Stage I ceramic processing development facility (PDF), and the use of Stage II ceramic PDF tools. Full-size membranes were prepared that meet the most stringent criterion for testing in the Technology Development Unit (TDU) under Task 4.3. Ceramatec is continuing to develop control charts for the repeated baseline processing. Ceramatec also established baseline ceramic processing for the entire set of ceramic components that are required to assemble and test full-size membranes in the TDU. Ceramatec successfully scaled up to the full-size oxygen exhaustpipe and end cap, and built inventories to support module assembly under Task 3.4 and ceramic-tometal seal testing under Task 1.2.

\section{Task 3.4: Subscale Module Fabrication}

Ceramatec initiated development of a process for assembling membrane modules from full-size components, by adapting the methods developed previously for subscale components. Tooling and specialized fixturing have been designed and fabricated to support this activity. Subscale modules of full-size membranes will be tested in the TDU under Task 4.3.

\section{Task 3.5: Advanced Module Development}

Ceramatec has continued to investigate an alternative bonding method for assembling ITM Oxygen membrane modules. Improvements achieved in processing conditions and procedures for the preferred 
system have enabled Ceramatec to perform trials of the novel bonding approach, and prepare in high yields test assemblies that are hermetic to helium at ambient temperature. Based on these results, Ceramatec will recommend the processing conditions and procedures for initial membrane module assembly trials with this "Advanced Module" method.

\section{Task 4.2: Design and Construction of the TDU}

The Technology Development Unit (TDU) pressure vessel was received and installed at the beginning of December at Air Products, completing milestone 4.2.1. Following the vessel installation, Air Products completed the welding of pipe sections and insulation of all hot sections. The TDU PLC system was delivered mid-December, and field wiring commenced. The TDU will be used to demonstrate the performance of full-size membrane components at commercially relevant conditions and oxygen productivities of up to 0.1 tons-per-day. 